\title{
Population and genetic status of a critically endangered species in Korea: Hydrangea luteovenosa (Hydrangeaceae)
}

\author{
Hyeok-Jae Choi*, Takuya Ito ${ }^{1}$, Masashi Yokogawa ${ }^{2}$, Shingo Kaneko ${ }^{3}$, \\ Yoshihisa Suyama ${ }^{4}$ and Yuji Isagi ${ }^{1}$ \\ Department of Biology and Chemistry, Changwon National University, Changwon 51140, Korea \\ ${ }^{1}$ Graduate School of Agriculture, Kyoto University, Kyoto 606-8502, Japan \\ ${ }^{2}$ Laboratory of Botany, Osaka Museum of Natural History, Osaka 546-0034, Japan \\ ${ }^{3}$ Department of Symbiotic Systems Science, Fukushima University, Fukushima 960-1296, Japan \\ ${ }^{4}$ Graduate School of Agricultural Science, Tohoku University, Miyagi 989-6711, Japan \\ (Received 19 January 2017; Revised 6 February 2017; Accepted 3 March 2017)
}

\begin{abstract}
The population status of Hydrangea luteovenosa Koidz. in Korea was investigated, with an emphasis on its genetic diversity. From field surveys, we obtained the only locality record for a wild population in Jeju Island, which contained 285 individuals in total. Genotyping was performed using five microsatellite markers for the all extant plants in Korea. Three Japanese populations were also genotyped for the comparative analyses. The genotyping result showed that the Jeju population consisted of only two multilocus genotypes, including identical heterozygous genotypes at two loci; it had been maintained mostly by vegetative reproduction; and although the Jeju population is geographically far from Japanese populations, all alleles observed in the Korean population were shared with Japanese populations, suggesting the possibility that H. luteovenosa in the Jeju Island had been recently migrated or introduced from Japan. Future ecological and genetic studies associated with negative effects of low genetic variation will be essential for determining the conservation direction of the threatened Korean population of this species.
\end{abstract}

Keywords: conservation, endangered species, Hydrangea luteovenosa, Korea, microsatellite

Many endangered species have small population sizes, sometimes, in extreme situations, with less than 10 remaining individuals (Li et al., 2012; Choi et al., 2013). Understanding the genetic and ecological characteristics of endangered plants or populations is important for the examination of the origin and conservation value (Isagi and Kaneko, 2014; Kaneko et al., 2017; Shiga et al., 2017) and development of effective conservation management programs (Izuno et al., 2012; Choi et al., 2013; Kaneko et al., 2013). The consequences of a small population size have received considerable research attention in the past decades (Ouborg et al., 2006; Li et al., 2012; Choi et al., 2013; Kaneko et al., 2013). In small populations, genetic drift and inbreeding can play essential roles in altering genetic variation, which can in turn influence persistence (Schaal et al., 1991; Neel and Ellstrand, 2001; Li et al., 2012). Both genetic drift and inbreeding represent potential threats for the persistence of small populations, as these processes can cause reduction of within-population genetic diversity (Ouborg et al., 2006; Willi et al., 2006) and inbreeding depression (Keller and Waller, 2002), respectively. Therefore, a precise evaluation of the current genetic status of critically endangered species or population is a necessary condition for successfully preventing their extinction (Bernardos et al. 2006).

In order to maximize the probability of success and to minimize the risk of failure of the conservation programs for critically endangered species, it is important to perform genotyping for all individuals of the target species using microsatellite markers (Izuno et al. 2012; Choi et al., 2013; Kaneko et al., 2013, 2017; Shiga et al., 2017). Analysis of the resulting genotypic data is likely to provide valuable

\footnotetext{
*Author for correspondence: hjchoi1975@changwon.ac.kr
} 
information, such as the exact amount of genetic diversity in both wild and ex situ populations, the kinship among remnant individuals, and the extent of inbreeding and outbreeding (Choi et al., 2013; Kaneko et al., 2013, 2017). This information also can help conservation managers to identify individuals that are of particular importance to maintain and recover the genetic diversity of the target species (Choi et al., 2013).

Hydrangea luteovenosa Koidz. (Hydrangeaceae Dumort.) is a deciduous shrub that grows on the forest floor of temperate forest in Jeju Island of Korea and western Japan (Kim, 2009). Although $H$. luteovenosa is common in Japan, it is listed as a critically endangered plant species in Korea at regional level based on the criteria of International Union for Conservation of Nature (Kim, 2009) with a noticeably small size population (Ito et al., 2013). Only one population has been known in Seongneol-oreum region of Mt. Hallasan in Jeju Island (Moon et al., 2004; Ito et al., 2013). In conservation of endangered species or population with limited distribution like $H$. luteovenosa in Korea, it is important to understand the ecological status such as its breeding and clonal distribution. Recently, Ito et al. (2013) developed microsatellite markers for this species in order to investigate its genetic status. Therefore, the main purpose of this research was to evaluate the population and genetic status of the critically endangered $H$. luteovenosa in Korea by complete genotyping of all known individuals using nuclear microsatellite markers.

\section{Materials and Methods}

\section{Census of the remnant population and sample collection}

We initially reviewed the data on the detailed distribution of $H$. luteovenosa from the recently available literature (Moon et al., 2004; Kim, 2009). From the result, we visited the only known locality on Jeju Island where H. luteovenosa had previously been reported, during the period July 14 to 15 and September 25, 2011. We also surveyed other areas considered suitable for this species in Seongneol-oreum region of Hallasan National Park. All wild individuals were mapped and sampled. To obtain more precise information on population structure, we examined pairwise geographic distance among individuals within the population. In addition, we visited three populations of Hyogo, Kagoshima, and Yamaguchi Prefectures in Japan, and collected leaf samples (43, 45, and 25 samples, respectively) (Fig. 1).

\section{DNA extraction, microsatellite genotyping, and analysis}

Total genomic DNA was extracted from approximately 10

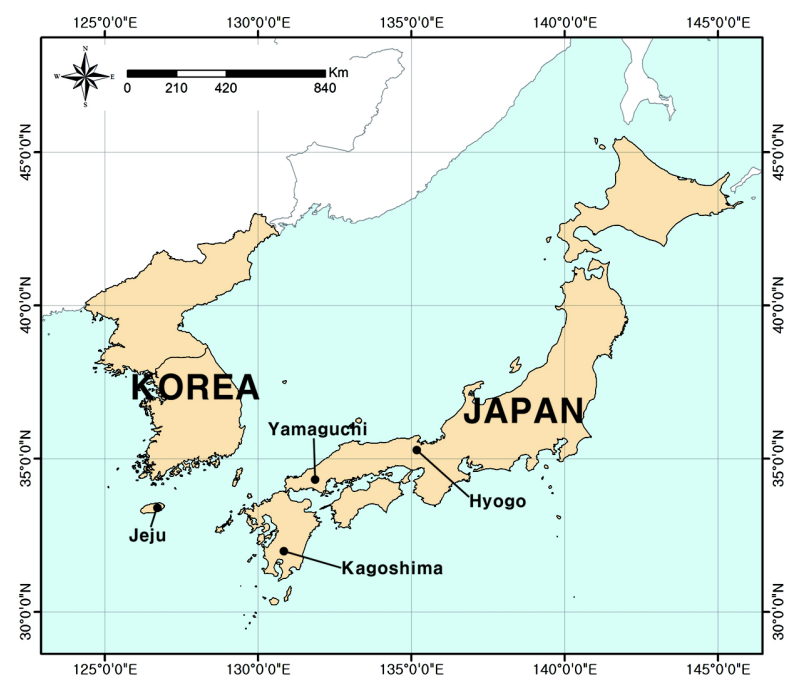

Fig. 1. A map showing the collection sites of Hydrangea luteovenosa in this study.

mg silica gel-dried leaf materials using a modified CTAB method (Milligan, 1992). All plant individuals were genotyped using five microsatellite loci recently developed for this species (Ito et al., 2013). Polymerase chain reaction (PCR) amplification mixtures were prepared following the standard protocol of the Qiagen Multiplex PCR Kit (Qiagen, Hilden, Germany) in a final volume of $10 \mu \mathrm{L}$, which contained $5 \mathrm{ng}$ of extracted DNA, $5 \mu \mathrm{L}$ of $2 \times$ Multiplex PCR Master Mix, and $0.2 \mu \mathrm{M}$ of each multiplexed primer. PCR amplifications were performed with the GeneAmp PCR System 2700 thermal cycler (Applied Biosystems, Foster City, CA, USA) using the following conditions: initial denaturation at $95^{\circ} \mathrm{C}$ for $15 \mathrm{~min}$, followed by 30 cycles of denaturation at $94^{\circ} \mathrm{C}$ for $30 \mathrm{~s}$, annealing at $54^{\circ} \mathrm{C}$ for $1 \mathrm{~min}$ $30 \mathrm{~s}$, extension at $72^{\circ} \mathrm{C}$ for $1 \mathrm{~min}$, and final extension at $60^{\circ} \mathrm{C}$ for $30 \mathrm{~min}$. The size of the PCR products was measured using a ABI PRISM 3100 Genetic Analyzer (Applied Biosystems) and GENOTYPER analysis software (Applied Biosystems).

The number of alleles per locus $(A)$, observed heterozygosity $\left(H_{\mathrm{O}}\right)$, and expected heterozygosity $\left(H_{\mathrm{E}}\right)$ were calculated to quantify genetic variation and connectivity in the Korean and Japanese populations. The significant deviation from HardyWeinberg equilibrium over all loci was tested by randomization using the FSTAT software (Goudet, 1995). Significance levels were adjusted using Bonferroni correction for multiple tests. Principal coordinate analysis (PCO) was also performed to evaluate genetic relationships among genotypes detected from Korean and Japanese populations using GenAlEx ver. 6.5 (Peakall and Smouse, 2012). 


\section{Results and Discussion}

\section{Population status}

The only wild population we recorded in this study occurred in the only previously known site (Standard coordinate: $33^{\circ} 22^{\prime} 017^{\prime \prime} \mathrm{N}, 126^{\circ} 38^{\prime} 027^{\prime \prime} \mathrm{E}$ ) in Jeju Island; we did not record any new locations for Korean $H$. leuteovenosa. The only Korean population located in the broad-leaved deciduous forest valley dominated by Quercus serrata Murray, Carpinus laxiflora (Siebold \& Zucc.) Blume, and Sasa palmata (Bean) E. G. Camus. Currently, the main threats to the wild population of Korean $H$. luteovenosa are (1) its small population size, consisting of 285 individuals (distribution area is ca. $5 \mathrm{~m} \times 64 \mathrm{~m}$ ) (Fig. 2), and (2) relatively small physical sizes of plants compared with plants in the larger Japanese population (Fig. 3). This small biological fitness can be affected by its relatively younger ages of plants compared to the Japanese population. However, it also might be influenced by negative genetic effects on population quality or inappropriate habitat environment.

\section{Genetic status}

Detailed genotyping was performed using five microsatellite markers for the all extant plants in Korea, and three Japanese populations were also genotyped for the comparative analyses (Table 1). Among the five microsatellite loci in Korean $H$. luteovenosa three showed polymorphism, and the number of alleles per locus $(A)$ is 1 or 2 (Table 1). The Jeju population of $H$. luteovenosa showed remarkably lower genetic diversity and number of genotypes than the Japanese populations, and did not have any specific allele in the five microsatellite loci (Table 1). The 285 samples collected from the Jeju population showed only two multilocus genotypes at the five loci (Table 1), and the dominating (ca. $88 \%$ ) genotype comprise by 251 individuals
(Genotype A in Fig. 2). PCO analysis showed an overlapping pattern of genetic relationship among the Japanese and Jeju genotypes (Fig. 4). This result suggests that the two genotypes

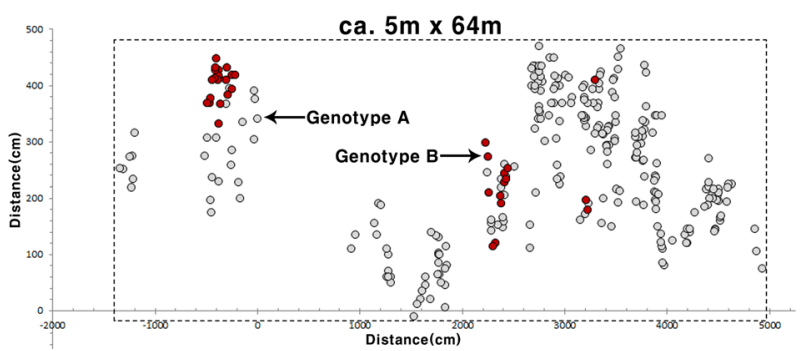

Fig. 2. Spatial distribution of all individuals with each genotype for Korean Hydrangea luteovenosa located on Jeju Island (standard coordinate: $\left.33^{\circ} 22^{\prime} 017^{\prime \prime} \mathrm{N}, 126^{\circ} 38^{\prime} 027^{\prime \prime} \mathrm{E}\right)$ in 2011.
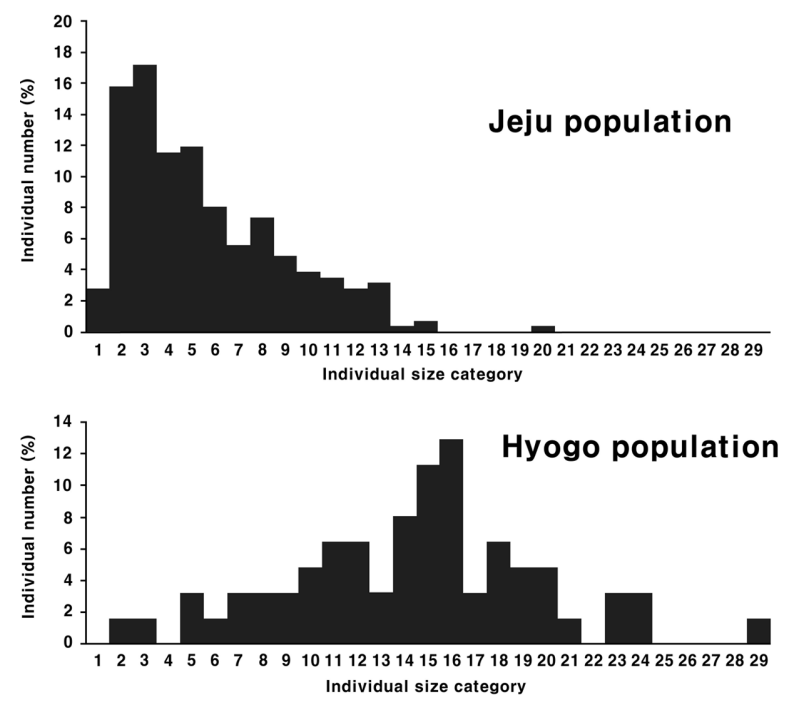

Fig. 3. Individual size plots of Hydrangea luteovenosa in Jeju (Korea) and Hyogo (Japan) populations. Individual size information (measured by maximum length of shoot) was divided into 29 categories and the graph shows the percentage of each category in the two populations.

Table 1. Variability of five microsatellite loci in four population of Hydrangea luteovenosa in Korea and Japan.

\begin{tabular}{|c|c|c|c|c|c|c|c|c|c|c|c|c|c|}
\hline \multirow[t]{2}{*}{ Loci } & \multicolumn{4}{|c|}{$\begin{array}{c}\text { Jeju (Korea) } \\
(n=285, \mathrm{G}=2)\end{array}$} & \multicolumn{3}{|c|}{$\begin{array}{l}\text { Hyogo (Japan) } \\
(n=43, \mathrm{G}=42)\end{array}$} & \multicolumn{3}{|c|}{$\begin{array}{c}\text { Kagoshima (Japan) } \\
(n=45, \mathrm{G}=45)\end{array}$} & \multicolumn{3}{|c|}{$\begin{array}{l}\text { Yamaguchi (Japan) } \\
(n=25, \mathrm{G}=24)\end{array}$} \\
\hline & $A$ & Genotype & $H_{\mathrm{O}}$ & $H_{\mathrm{E}}$ & $A$ & $H_{\mathrm{O}}$ & $H_{\mathrm{E}}$ & $A$ & $H_{\mathrm{O}}$ & $H_{\mathrm{E}}$ & $A$ & $H_{\mathrm{O}}$ & $H_{\mathrm{E}}$ \\
\hline Hlut 157 & 2 & $(219,225)$ & $1.00^{\mathrm{a}}$ & 0.50 & 13 & 0.81 & 0.86 & 18 & 0.84 & 0.92 & 15 & 0.81 & 0.83 \\
\hline Hlut170 & 1 & $(151,151)$ & $0.00^{\mathrm{a}}$ & 0.00 & $x$ & - & - & $x$ & - & - & $\times$ & - & - \\
\hline Hlut 214 & 2 & $(146,150)$ & $1.00^{\mathrm{a}}$ & 0.50 & 9 & $0.45^{*}$ & 0.8 & 6 & $0.47 *$ & 0.52 & 2 & $0.08^{*}$ & 0.18 \\
\hline Hlut226 & 1 & $(172,172)$ & $0.00^{\mathrm{a}}$ & 0.00 & 3 & 0.45 & 0.43 & 2 & 0.44 & 0.47 & 2 & 0.04 & 0.04 \\
\hline Hlut234 & 2 & $\begin{array}{l}\mathrm{A}(219,221), \\
\mathrm{B}(221,221)\end{array}$ & $0.93^{\mathrm{a}}$ & 0.50 & 15 & $0.48^{*}$ & 0.9 & 21 & 0.71 & 0.76 & 11 & 0.73 & 0.83 \\
\hline
\end{tabular}

$\times$ indicates that the locus was not amplified.

*A significant deviation from Hardy-Weinberg equilibrium (HWE) expectations is indicated by $\mathrm{p}<0.05$.

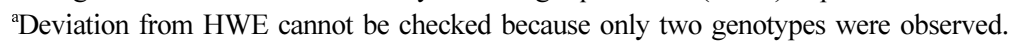




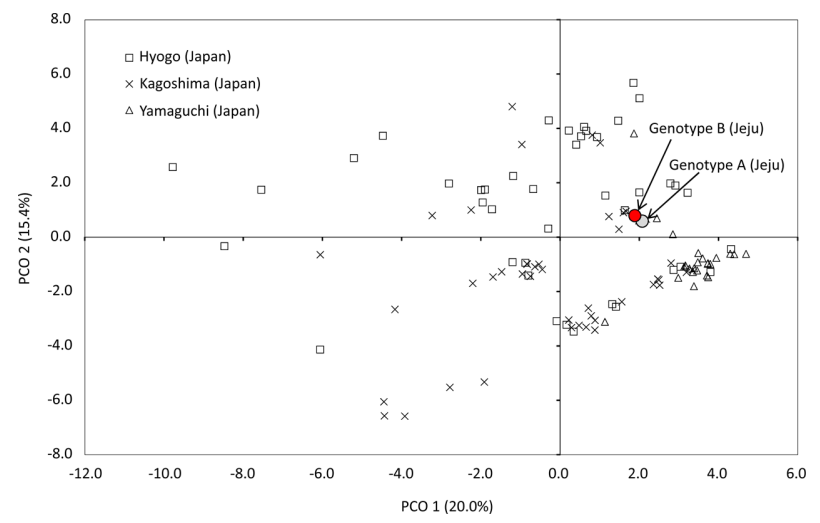

Fig. 4. Principal coordinate (PCO) analysis of 113 genotypes in Jeju and three Japanese populations.

observed from Jeju Island have no genetic specificity in terms of their alleles. More or less disjunct distribution of individuals in each genotype (Fig. 2) might be influenced by irregular environmental features including valley overflow during the rainy season together with physical obstacles such as rocks and a forest road crossing the habitat (H. J. Choi et al., pers. obs.)

From the result we can conclude, (1) the Jeju population having 285 individuals consisted of only two multilocus genotypes, including identical heterozygous genotypes at two loci indicating without the recombination of sexual reproduction, (2) this predominance of only two genotypes was not observed from native Japanese populations, and (3) although the Jeju population is geographically far from Japanese populations, all alleles observed in the Korean population were shared with Japanese populations, suggesting the possibility that $H$. luteovenosa in the Jeju Island had been recently migrated or introduced from Japan.

Unfortunately, it is difficult to determine exact origin of Korean H. luteovenosa. There is no appropriate approach that can examine the man-introduced origin hypothesis based on present study. However, a genetic analysis about "Endangered" species suspected of man-introduced origin also reported the quite low genetic variation (Isagi and Kaneko, 2014; Kaneko et al., 2017). The results of these previous studies are similar in the current genetic status of Korean $H$. luteovenosa population and might support man-introduced origin hypothesis.

\section{Implication for conservation}

The Korean $H$. luteovenosa is considered as critically endangered plant species in Korea at regional level (Kim, 2009) with a noticeably small size population (Ito et al., 2013). Our results showed remarkably low genetic diversity especially by vegetative reproduction in the Korean population (Table 1).
However, the present findings might also demand a reconsideration of the conservation status and especially origin of Korean $H$. luteovenosa. Future ecological and genetic studies associated with negative effects of low genetic variation will be essential for determining the conservation direction of the threatened Korean population of this species.

\section{Acknowledgments}

We thank C.S. Kim, T. Abe, and Y. Ohta for their helpful support of sampling. This research was supported by the Environment Research and Technology Development Fund (S9-2) of the Ministry of the Environment, Japan.

\section{Literatures Cited}

Bernardos, S., A. Amado and F. Amich. 2006. The narrow endemic Scrophularia valdesii Ortega-Olivencia \& Devesa (Scrophulariaceae) in the Iberian Peninsula: an evaluation of its conservation status. Biodiversity and Conservation 15 : 4027-4043.

Choi, H.-J., S. Kaneko, M. Yokogawa, G.-P. Song, D.-S. Kim, S.H. Kang, Y. Suyama and Y. Isagi. 2013. Population and genetic status of a critically endangered species in Korea, Euchresta japonica (Leguminosae), and their implication for conservation. Journal of Plant Biology 56: 251-257.

Goudet, J. 1995. FSTAT (version 1.2): a computer program to calculate F-statistics. Journal of Heredity 86: 485-486.

Isagi, Y. and S. Kaneko. 2014. Ubiquitous genotyping for conservation of endangered plant species. In Integrative Observations and Assessments. Nakano, S., T. Yahara and T. Nakashizuka (eds.), Springer, Tokyo. Pp. 311-325.

Ito, T., S. Kaneko, M. Yokogawa, G.-P. Song, H.-J. Choi and Y. Iasagi. 2013. Isolation and characterization of microsatellite markers for Hydrangea luteovenosa (Hydrangeaceae), an endangered species in Korea. Korean Journal of Plant Taxanomy 43: 30-33.

Izuno, A., M. Takamiya, S. Kaneko and Y. Isagi. 2012. Genetic variation and structure of the endangered Lady Fern Athyrium viridescentipes based on ubiquitous genotyping. Journal of Plant Research 125: 613-618.

Kaneko, S., T. Abe and Y. Isagi. 2013. Complete genotyping in conservation genetics, a case study of a critically endangered shrub, Stachyurus macrocarpus var. prunifolius (Stachyuraceae) in the Ogasawara Islands, Japan. Journal of Plant Research 126: 635-642.

Kaneko, S., Y. Matsuki, Y.-X. Qiu and Y. Isagi. 2017. Chloroplast DNA sequencing and detailed microsatellite genotyping of all 
remnant populations suggests that only a single genet survives of the critically endangered plant Rehmannia japonica. Journal of Plant Research 130: 117-124.

Keller, L. F. and D. M. Waller. 2002. Inbreeding effect in wild populations. Trends in Ecology and Evolution 17: 230-241.

Kim, C.-S. 2009. Vascular plant diversity of Jeju Island, Korea. Korean Journal of Plant Resources 22: 558-570.

Li, Y.-Y., S.-M. Guan, S.-Z. Yang, Y. Luo and X.-Y. Chen. 2012. Genetic decline and inbreeding depression in an extremely rare tree. Conservation Genetics 13: 343-347.

Milligan, B. 1992. Plant DNA isolation. In Molecular genetic analysis of populations: a practical approach. Hoelzel. A. R. (ed.), IRL Press, Oxford, Pp. 59-88.

Moon, M. O., Y. J. Kang, C. H. Kim and C.-S. Kim. 2004. An unrecorded species in Korea flora: Hydrangea luteovenosa Koidz. (Hydrangeaceae). Korean Journal of Plant Taxonomy 34: 1-7. (in Korean)

Neel, M. C. and N. C. Ellstrand. 2001. Patterns of allozyme diversity in the threatened plant Erigeron parishii (Asteraceae). American Journal of Botany 88: 810-818.
Ouborg, N. J., P. Vergeer and C. Mix. 2006. The rough edges of the conservation genetics paradigm for plants. Journal of Ecology 94: 1233-1248.

Peakall, R. and P. E. Smouse. 2012. GenAlEx 6.5: genetic analysis in Excel. Population genetic software for teaching and research: an update. Bioinformatics 28: 2537-2539.

Schaal, B. A., W. J. Leverich and S. H. Rogstad. 1991. A comparison of methods for assessing genetic variation in plant conservation biology. In Genetics and Conservation of Rare Plants. Falk, D. A. and K. E. Holsinger (eds.), Oxford University Press, New York. Pp. 123-134.

Shiga, T., M. Yokogawa, S. Kaneko and Y. Isagi. 2017. Genetic diversity and population structure of Nuphar submersa (Nymphaeaceae), a critically endangered aquatic plant endemic to Japan, and implications for its conservation. Journal of Plant Research 130: 83-93.

Willi, Y., J. Van Buskirk and A. A. Hoffmann. 2006. Limits to the adaptive potential of small populations. Annual Review of Ecology, Evolution, and Systematics 37: 433-458. 